\title{
Chronic hypoxaemia and gender status modulate adiponectin plasmatic level and its multimer proportion in severe COPD patients: new endotypic presentation?
}

Mélany Pierard ${ }^{1}$, Alexandra Tassin ${ }^{1}$, Antoine Legrand ${ }^{1}$ and Alexandre Legrand ${ }^{1,2^{*}}$ (D)

\begin{abstract}
Background: Disease progression in COPD patient is associated to lung function decline, leading to a higher risk of hypoxaemia and associated comorbidities, notably cardiovascular diseases (CVD). Adiponectin (Ad) is an adipokine with cardio-protective properties. In COPD patients, conflicting results were previously reported regarding Ad plasmatic $\left(\mathrm{Ad}_{\mathrm{pl}}\right)$ level, probably because COPD is a heterogeneous disease with multifactorial influence. Among these factors, gender and hypoxaemia could interact in a variety of ways with Ad pathway. Therefore, we postulated that these components could influence $\mathrm{Ad}_{\mathrm{pl}}$ level and its multimers in COPD patients and contribute to the appearance of a distinct endotype associated to an altered CVD risk.
\end{abstract}

Methods: One hundred COPD patients were recruited: 61 were men and 39 were women. Patients who were not severely hypoxemic were allocated to non-hypoxemic group which included 46 patients: 27 men and 19 women. Hypoxemic group included 54 patients: 34 men and 20 women. For all patients, $\mathrm{Ad}_{\mathrm{pl}}$ level and proportion of its different forms were measured. Differences between groups were evaluated by Rank-Sum tests. The relationship between these measures and $\mathrm{BMl}$, blood gas analysis $\left(\mathrm{PaO}_{2}, \mathrm{PaCO}_{2}\right)$, or lung function (FEV1, FEV1/FVC, TL $\mathrm{CO}$, TLC, RV) were evaluated by Pearson correlation analysis.

Results: Despite similar age, BMI and obstruction severity, women had a higher TLC and RV (median: TLC $=105 \%$; $\mathrm{RV}=166 \%$ ) than men (median: $\mathrm{TLC}=87 \%$; RV $=132 \%$ ). Adpl level was higher in women (median $=11,152 \mathrm{ng} / \mathrm{ml}$ ) than in men (median $=10,239 \mathrm{ng} / \mathrm{ml}$ ) and was negatively associated with hyperinflation $(R=-0,43)$ and hypercapnia $(R=-0,42)$. The proportion of the most active forms of Ad (HMW) was increased in hypoxemic women (median $=10 \%$ ) compared with non-hypoxemic women (median $=8 \%$ ) but was not modulated in men.

Conclusion: COPD pathophysiology seemed to be different in hypoxemic women and was associated to Ad modulations. Hyperinflation and air-trapping in association with hypercapnia and hypoxaemia, could contribute to a modulation of $\mathrm{Ad}_{\mathrm{pl}}$ level and of its HMW forms. These results suggest the development of a distinct endotypic presentation, based on gender.

Keywords: COPD, Gender difference, Hypoxaemia, Hypoxia, Adiponectin, Multimers

\footnotetext{
* Correspondence: alexandre.legrand@umons.ac.be

'Laboratory of Respiratory Physiology, Pathophysiology and Rehabilitation, Research Institute for Health Sciences and Technology, University of Mons, Avenue du Champ de Mars, 6, B-7000 Mons, Belgium

${ }^{2}$ Department of Pneumology, Erasme Hospital, Brussels, Belgium
}

(c) The Author(s). 2020 Open Access This article is licensed under a Creative Commons Attribution 4.0 International License, which permits use, sharing, adaptation, distribution and reproduction in any medium or format, as long as you give appropriate credit to the original author(s) and the source, provide a link to the Creative Commons licence, and indicate if changes were made. The images or other third party material in this article are included in the article's Creative Commons. licence, unless indicated otherwise in a credit line to the material. If material is not included in the article's Creative Commons licence and your intended use is not permitted by statutory regulation or exceeds the permitted use, you will need to obtain permission directly from the copyright holder. To view a copy of this licence, visit http://creativecommons.org/licenses/by/4.0/ The Creative Commons Public Domain Dedication waiver (http://creativecommons.org/publicdomain/zero/1.0/) applies to the data made available in this article, unless otherwise stated in a credit line to the data. 


\section{Background}

Chronic obstructive pulmonary disease (COPD) is a progressive disease associated with lung function decline and comorbidities such as cardiovascular diseases (CVD). By inducing secondary erythrocytosis, endothelial dysfunction, and pulmonary arterial hypertension, hypoxaemia in severe COPD patients was suggested to contribute to the increased CVD risk in these patients $[1,2]$. The prevalence of the disease is increasing among women due to the higher smoking rate $[3,4]$. Moreover, sex-differences were reported in the course of the disease. Women were described to exhibit a greater susceptibility to tobacco, faster annual decline of lung function and worse quality of life $[3,4]$. This increased effect of tobacco smoke on women was suggested to be due to gender differences in airway structure [5-7], but inflammatory response to tobacco smoke was also suspected to differ at the level of the small airways [8] and to be at the origin of a more extensive airway remodelling [9]. The prevalence of co-morbidities also varies with gender in COPD patients and men were described to be more susceptible to CVD and diabetes mellitus [10].

Adiponectin (Ad), a $30 \mathrm{kDa}$ protein mainly secreted by adipose tissue, was well described for its anti-inflammatory, anti-atherogenic and anti-diabetic effects [11]. The physiological plasmatic concentration of this adipokine is higher in women [12]. In circulating blood, Ad was detected in 3 different isoforms: low (LMW), medium (MMW), and high molecular weight forms (HMW). This latter form was described as the most active isoform: it was better correlated to insulin sensitivity and circulating glucose concentration $[13,14]$. A reduced Ad plasmatic $\left(\mathrm{Ad}_{\mathrm{pl}}\right)$ level was associated to multiple metabolic and CVD disorders [15]. In COPD patients, conflicting results regarding $\mathrm{Ad}_{\mathrm{pl}}$ level were observed in previous studies [16-18] and could be explained by the heterogeneity of the disease. Several factors, such as exacerbation rate, BMI, disease severity and progression were associated to differences in $\mathrm{Ad}_{\mathrm{pl}}$ level in COPD [16, 19-22]. In addition, exposure to chronic hypoxia was also shown to alter Ad expression in adipocytes in vitro, and in adipose tissue in vivo [23-25].

Adiponectin was previously proposed as a biomarker for COPD risk management, and its pathway was suggested as a potential therapeutic target $[20,26]$. However, COPD is a complex and heterogeneous disease [27] that could interact in a variety of ways with Ad pathway [16, 19-22]. In this study, we therefore evaluated $\mathrm{Ad}_{\mathrm{pl}}$ level and the proportion of HMW forms in COPD patients, with a special attention to gender and hypoxaemia effects. Potential relationships between these data and lung function were also evaluated.

\section{Methods}

\section{Subjects}

One hundred COPD patients were recruited from the outpatient clinic of a tertiary University Hospital from
2016 to 2018 and were referred for evaluation of need for oxygen therapy or for the adaptation of this treatment. COPD was diagnosed according to the ACCP/ATS/ERS guidelines [28] and severity of their airflow limitation was defined according to GOLD criteria, described in [29].

In this study, patients were divided into several groups according to gender and/or the severity of hypoxaemia. Among all patients of the study, 61 were men and 39 women. Concerning the hypoxaemia, patients were affected the hypoxemic group when they were severely hypoxemic patients $\left(\mathrm{PaO}_{2} \leq 55 \mathrm{mmHg}\right)$ or to the nonhypoxemic group when their $\mathrm{PaO}_{2}$ was above $55 \mathrm{mmHg}$, while breathing room air. This cut-off was based on ATS/ERS statement in which severe hypoxaemic COPD patients were defined as patients exhibiting a $\mathrm{PaO}_{2} \leq 55$ $\mathrm{mmHg}$. Non-hypoxemic group included 46 patients (27 men and 19 women), whereas hypoxemic group included 54 patients ( 34 men and 20 women).

Patients with significant comorbidities such as malignancy, endocrine, liver, or gastrointestinal disorders, primitive cardiovascular abnormalities, or a recent surgery were excluded. All subjects were older than 40 years of age. This study was approved by the Erasme Hospital Ethics Committee and conducted in accordance with the Helsinki Declaration.

Patients' data including age, gender and BMI were collected, and analyses were performed anonymously. Arterial blood samples were obtained at rest, with the patient in the sitting position, while breathing room air. Arterial oxygen $\left(\mathrm{PaO}_{2}\right)$ and carbon dioxide $\left(\mathrm{PaCO}_{2}\right)$ partial pressures were measured and recorded. Spirometry, lung volumes and single-breath determination of carbon monoxide uptake were then evaluated according to the ATS guidelines [30-32] (M.E.C PFT systems Body ${ }^{\mathrm{Tm}}$ and Diff $^{\mathrm{m}}$, Belgium) and expressed as a percentage of the predicted value (\%pv). FEV1 (forced expiratory volume in one second) and FVC (forced vital capacity), FEV1/FVC ratio, carbon monoxide transfer factor $\left(\mathrm{TL}_{\mathrm{CO}}\right)$, total lung capacity (TLC), and residual volume (RV) were recorded. As patients did not interrupt their medical treatment before medical appointment, these measures could be reasonably considered as post-bronchodilation data. TLC and RV have not been obtained from 2 nonhypoxemic women and 5 men because they were unable to perform plethysmography in a reproducible way.

\section{Adiponectin plasmatic level measurement}

$\mathrm{Ad}_{\mathrm{pl}}$ level was measured according to the manufacturer's instructions (DRP300: Human Total Adiponectin/Acrp30 Quantikine ELISA Kit, R\&D Systems). Assay sensitivity was estimated at $0.891 \mathrm{ng} / \mathrm{ml}$ and assay range was between 3.9 and $250 \mathrm{ng} / \mathrm{ml}$. Patient samples were diluted according to the manufacturer's instructions in order to be within the predefined range. 


\section{Adiponectin oligomer distribution determined by Western blot}

The relative amounts of LMW, MMW and HMW Admer were evaluated for each patient as previously described in Pierard et al. [33]. These amounts were determined using a non-denaturing PAGE-SDS followed by a Western blot [33]. Five microliter of plasma diluted to contain $5 \mu \mathrm{g} / \mathrm{ml}$ of Ad were loaded onto a $6 \%$ polyacrylamide gel in the presence of SDS [33]. For the Western blot, proteins were transferred to a nitrocellulose membrane (Millipore, Darmstadt, Germany) [33]. After blocking with 5\% fat-free dry milk-TBS, the membranes were incubated with a rabbit polyclonal primary antibody directed against Ad (Ab85827, 1:1000, Abcam, Cambridge, UK) [33]. The membranes were then incubated with a horseradish peroxidase-labelled secondary antibody (1:5000, SigmaAldrich, St. Louis, MO, USA) [33]. The ECL ${ }^{\mathrm{T}}$ Western Blotting Detection kit (GE Healthcare, Little Chalfont, UK) was used for the revelation step [33]. The immunoreactive bands were then submitted to a densitometric analysis using the Image J software to determine the proportion of LMW, MMW and HMW forms [33].

\section{Statistical analysis}

Sample size was estimated for a 4-group ANOVA study with a power of 0.8 and the significance level at 0.05 . The expected difference in means was based on the difference in HMW\% observed in mice [34] and the variation among experimental subjects was arbitrarily considered as twice as high as in this mouse study. The total sample size was rounded to 100 patients. A Rank-Sum test was used to evaluate differences between groups. In the tables, results were represented as median and 5th-95th percentiles. In the graphs, all data were represented as boxplots (5th-95th percentiles; dots are outliers). Pearson's coefficient was used for correlation analyses. Pearson correlation coefficient (R) was calculated between every lung function parameter and $\mathrm{Ad}_{\mathrm{pl}}$ level measured by ELISA or HMW form proportion determined by non-denaturant SDS-PAGE followed by a Western blot. All representative blots were included in supplementary material 1 and all data obtained to perform these correlations were included in supplementary material 2. Differences were considered statistically significant at a $P$ value $<0.05$. All statistical analyses were performed with Sigma Plot 11.0 Software (Systat Software, USA).

Table 1 Clinical characteristics of COPD subjects separated according to gender or hypoxaemia status. Median [25th - 75th percentiles]. * $p<0.05 ;{ }^{* *} p<0,001$; Rank-Sum test

\begin{tabular}{|c|c|c|c|}
\hline & $\begin{array}{l}\text { Non-hypoxemic } \\
(n=46)\end{array}$ & $\begin{array}{l}\text { Hypoxemic } \\
(n=54)\end{array}$ & $P$ value \\
\hline Age (year) & 68 [65-76] & $71,5[64-77]$ & 0,745 \\
\hline BMI $\left(\mathrm{kg} / \mathrm{m}^{2}\right)$ & $24,3[20,2-30,5]$ & $25,8[22,4-30,1]$ & 0,531 \\
\hline $\mathrm{PaO}_{2}(\mathrm{mmHg})$ & 62 [59-66] & $47[41-51]$ & $<0,001^{* *}$ \\
\hline $\mathrm{PaCO}_{2}(\mathrm{mmHg})$ & 41 [37-44] & $45,5[39-53]$ & $0,002^{*}$ \\
\hline pH & $7,42[7,40-7,45]$ & $7,42[7,38-7,44]$ & 0,535 \\
\hline $\mathrm{FEV}_{1}(\% \mathrm{pv})$ & $34,5\left[29^{-} 46\right]$ & $31_{[25-44]}$ & 0,186 \\
\hline $\mathrm{FEV}_{1} / \mathrm{FVC}$ & $46,8[38-58]$ & $46,3[39,5-52]$ & 0,445 \\
\hline $\mathrm{TL}_{\mathrm{CO}}(\% \mathrm{pv})$ & $39,5[32,5-49,5]$ & $29,5[23-42,8]$ & $0,002^{*}$ \\
\hline TLC (\% pv) & 91 [79-104,8] & $97,5[82-109,8]$ & 0,225 \\
\hline RV (\%pv) & $143[117,5-171]$ & $152,65[114-202,5]$ & 0,334 \\
\hline \multirow[t]{2}{*}{ 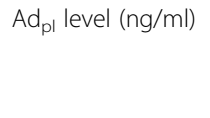 } & $11,599,1[6021,6-15,073,0]$ & $9804,7[5857,8-13,306,2]$ & 0,483 \\
\hline & $\begin{array}{l}\text { Men } \\
(n=61)\end{array}$ & $\begin{array}{l}\text { Women } \\
(n=39)\end{array}$ & \\
\hline Age (year) & $72[66,7-77,2]$ & $67[60-74,7]$ & 0,061 \\
\hline BMI $\left(\mathrm{kg} / \mathrm{m}^{2}\right)$ & $25,6[22,4-30,5]$ & $24,8[20,3-30,6]$ & 0,799 \\
\hline $\mathrm{PaO}_{2}(\mathrm{mmHg})$ & $54_{[45-60,5]}$ & $55_{[47-61,7]}$ & 0,538 \\
\hline $\mathrm{PaCO}_{2}(\mathrm{mmHg})$ & $42[37-47]$ & $45_{[40-50]}$ & 0,127 \\
\hline pH & $7,42[7,40-7,44]$ & $7,42[7,39-7,45]$ & 0,450 \\
\hline $\mathrm{FEV}_{1}(\% \mathrm{pv})$ & $32[25,7-44,2]$ & $34[27,2-46]$ & 0,424 \\
\hline $\mathrm{FEV}_{1} / \mathrm{FVC}$ & $47[39,7-55,2]$ & $45,8[39,0-54,8]$ & 0,835 \\
\hline$T L_{C O}(\% p v)$ & $35[26,6-50,5]$ & $32,9[24-43,3]$ & 0,254 \\
\hline TLC (\% pv) & $87,35[74,5-102,5]$ & 105,4 [90-116] & $<0,001^{* *}$ \\
\hline RV (\%pv) & 132,3 [104-179] & 166,25 [138-195] & $0,008^{*}$ \\
\hline $\mathrm{Ad}_{\mathrm{pl}}$ level (ng/ml) & $10,239,2[5265,7-13,062,8]$ & $11,152,232[7549,7-19,022,8]$ & $0,044^{*}$ \\
\hline
\end{tabular}




\section{Results}

\section{Characteristics of subjects}

One hundred COPD patients with moderate (16\%), severe $(43 \%)$ or very severe obstruction $(41 \%)$ were included in this study. $61 \%$ of the cohort were male. $46 \%$ were not severely hypoxemic and allocated to the nonhypoxemic group (Table 1). On average, hypoxemic and non-hypoxemic patients exhibited the same age, BMI and disease severity based on FEV1 value. Both groups had a significant air trapping (increased RV). The alteration of $\mathrm{TL}_{\mathrm{CO}}$ was more severe in hypoxemic patients and these patients were more hypercapnic than nonhypoxemic counterparts. When the cohort was separated according to gender, no difference was observed for age, BMI, FEV1, $\mathrm{PaCO}_{2}$ or $\mathrm{TL}_{\mathrm{CO}}$. However, we found an increased TLC and RV in women compared with men.

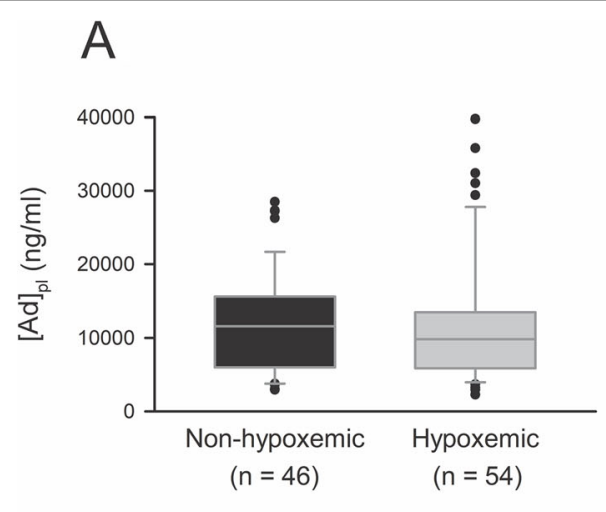

B

C
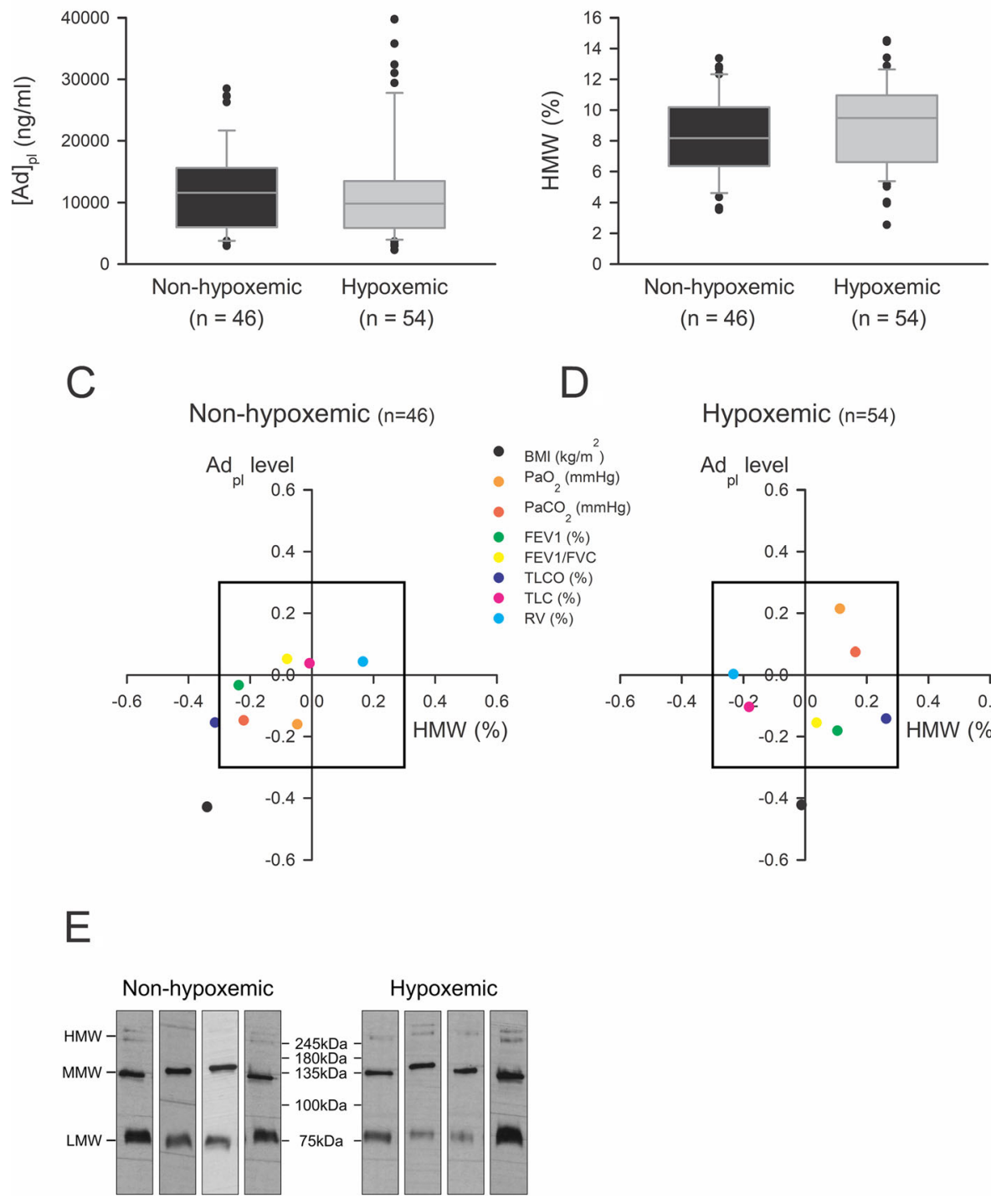

D

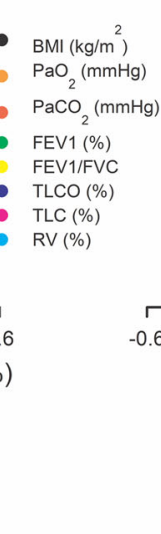

Hypoxemic $(n=54)$

Fig. 1 a-b Adpl level (a) and HMW form proportion (b) in non-hypoxemic and hypoxemic COPD patients. Adpl level was measured by ELISA and HMW form proportion was determined using a non-denaturing PAGE-SDS followed by a Western blot. Data were represented as boxplots (5th and 95th percentiles). Rank-Sum test: NS. c-d Correlation between lung function parameters and $\mathrm{Ad}_{\mathrm{pl}}$ level (vertical) or HMW form proportion (horizontal), in non-hypoxemic (c) and hypoxemic (d) COPD patients. Pearson correlation coefficients (R) between every parameter and either Adpl level or HMW form proportion were calculated and represented as a point on the graph. The box in the graph represents the critical value for Pearson correlation coefficient to obtain a $p<0.05$. Therefore, every point outside the box corresponds to a significant correlation. e Representative blots of Ad form proportions in hypoxemic and non-hypoxemic patients, determined by using non-denaturant PAGE-SDS followed by a Western blot. HMW forms correspond to the higher molecular weight bands. Admer/total Ad ratios were obtained after densitometric analysis 
Effect of hypoxaemia on $\mathrm{Ad}_{\mathrm{pl}}$ level and $\mathrm{HMW}$ forms We did not observe any difference in $\mathrm{Ad}_{\mathrm{pl}}$ level and in HMW form proportion between hypoxemic and nonhypoxemic patients (Fig. 1a-b, e). We found that $\mathrm{Ad}_{\mathrm{pl}}$ level was negatively correlated with BMI in both groups but was not correlated with other parameters (Fig. 1c-d, Table 2). We detected a significant negative correlation between BMI and HMW form proportion in non-hypoxemic patients, but not in the hypoxemic group. Moreover, a negative correlation was observed between HMW forms and $\mathrm{TL}_{\mathrm{CO}}$ in non-hypoxemic patients. In the hypoxemic group, these parameters were positively correlated but without reaching a statistically significant level $(p=0.055)$.

Impact of gender difference on $\mathrm{Ad}_{\mathrm{pl}}$ level and $\mathrm{HMW}$ forms As gender differences in total and HMW Ad levels were previously observed in many studies [35, 36], we evaluated these parameters in men and women and correlated these values with lung function parameters. We found a higher $\mathrm{Ad}_{\mathrm{pl}}$ level in women compared with men, while no difference between HMW form proportions was observed (Fig. 2a-b, e). As previously, in both groups, $\mathrm{Ad}_{\mathrm{pl}}$ level was negatively correlated with BMI (Fig. 2c-d, Table 3). In women, we observed a significant negative correlation between $\mathrm{Ad}_{\mathrm{pl}}$ level and TLC, as well as with $\mathrm{PaCO}_{2}$. These observations were in accordance with the decrease of $\mathrm{Ad}_{\mathrm{pl}}$ level in hypercapnic women $\left(\mathrm{PaCO}_{2}>\right.$ $45 \mathrm{mmHg})$ compared with normocapnic women $(p<$ 0.05) (Fig. 3a). A reduced $\mathrm{Ad}_{\mathrm{pl}}$ level was also observed in women characterized by hyperinflated lungs (TLC> $115 \%$ pv) (Fig. 3b). Concerning HMW form proportion, no gender difference and no correlation with BMI, arterial gas values, or lung parameters were detected.

\section{Effect of combined gender difference and hypoxia on $\mathrm{Ad}_{\mathrm{pl}}$ level and $\mathrm{HMW}$ forms}

We did not observe any modification in total or HMW Ad level between hypoxemic and non-hypoxemic men
(Fig. 4). In women, hypoxaemia did not modify total $\operatorname{Ad}_{\mathrm{pl}}$ level but increased HMW form proportion. Indeed, as shown on representative blots (Fig. 4f), the higher bands, corresponding to HMW Ad forms, are more intense in hypoxemic women compared with non-hypoxemic women. As previously, whatever the gender, $\mathrm{Ad}_{\mathrm{pl}}$ level was negatively correlated with BMI in hypoxemic and nonhypoxemic groups (Fig. 5, Table 4). A negative correlation between total $\mathrm{Ad}_{\mathrm{pl}}$ level and TLC was statistically significant in non-hypoxemic women, and borderline in hypoxemic women $(p=0.07)$. Ad $\mathrm{d}_{\mathrm{pl}}$ level was also negatively correlated with $\mathrm{PaCO}_{2}$ in hypoxemic women. Regarding HMW forms, we observed a positive correlation between HMW proportion and RV in non-hypoxemic men (Fig. 5, Table 5). We also detected an opposite relationship between $\mathrm{TL}_{\mathrm{CO}}$ and HMW level in hypoxemic and nonhypoxemic men. While a positive correlation was observed in hypoxemic men, a negative correlation was detected in non-hypoxemic men. This relationship did not appear in women. Although, we observed that HMW level was negatively associated with RV in hypoxemic women.

\section{Discussion}

We postulated that gender and hypoxaemia could influence $\mathrm{Ad}_{\mathrm{pl}}$ level as well as its multimers and therefore contribute to the appearance of a distinct endotype associated to an altered CVD risk. Our results showed a gender difference in $\mathrm{Ad}_{\mathrm{pl}}$ level. Women exhibited a higher $\mathrm{Ad}_{\mathrm{pl}}$ level compared with men. While this discrepancy was previously described [37, 38], the mechanism underlying this divergence is still investigated. Testosterone level [39-42] and the difference in adipose tissue distribution between men and women were previously mentioned [43]. Other mechanisms could also explain this gender variation in $\mathrm{Ad}_{\mathrm{pl}}$ level in COPD patients. In our study, differences in men and women $\mathrm{Ad}_{\mathrm{pl}}$ level were associated with divergent clinical characteristics, among which the increased TCL

Table 2 Correlation between lung function parameters and $\mathrm{Ad}_{\mathrm{pl}}$ level or $\mathrm{HMW}$ form proportion in non-hypoxemic and hypoxemic COPD patients. Adpl level was measured by ELISA and HMW form proportion was determined using a non-denaturing PAGE-SDS followed by a Western blot. Data were represented as Pearson correlation coefficient ( $p$ value)

\begin{tabular}{|c|c|c|c|c|}
\hline \multirow[b]{2}{*}{ Correlation } & \multicolumn{2}{|l|}{ Ad $_{\mathrm{pl}}$ level } & \multicolumn{2}{|l|}{ HMW form proportion (\%) } \\
\hline & Non-hypoxemic $(n=46)$ & Hypoxemic $(n=54)$ & Non-hypoxemic $(n=46)$ & Hypoxemic $(n=54)$ \\
\hline $\mathrm{BMI}\left(\mathrm{kg} / \mathrm{m}^{2}\right)$ & $-0,428_{(p=0,003)}$ & $-0,422^{*}(p=0,001)$ & $-0,340^{*}(p=0,021)$ & $-0,012_{(p=0,934)}$ \\
\hline $\mathrm{PaO}_{2}(\mathrm{mmHg})$ & $-0,161_{(p=0,287)}$ & $0,214(p=0,120)$ & $-0,047(p=0,757)$ & $0,113(p=0,416)$ \\
\hline $\mathrm{PaCO}_{2}(\mathrm{mmHg})$ & $-0,148(p=0,328)$ & $0,074(p=0,600)$ & $-0,221(p=0,141)$ & $0,163(p=0,247)$ \\
\hline FEV1 (\%pv) & $-0,033(p=0,826)$ & $-0,181(p=0,190)$ & $-0,237(p=0,113)$ & $0,105(p=0,451)$ \\
\hline FEV1/FVC & $0,052(p=0,732)$ & $-0,155_{(p=0,262)}$ & $-0,080(p=0,598)$ & $0,038(p=0,787)$ \\
\hline $\mathrm{TL}_{\mathrm{CO}}(\% \mathrm{pv})$ & $-0,155(p=0,315)$ & $-0,142(p=0,306)$ & $-0,314^{*}(p=0,043)$ & $0,263(p=0,055)$ \\
\hline TLC (\%pv) & $0,038(p=0,811)$ & $-0,104(p=0,464)$ & $-0,007(p=0,963)$ & $-0,181(p=0,198)$ \\
\hline RV (\%pv) & $0,043(p=0,786)$ & $0,003(p=0,983)$ & $0,166_{(p=0,294)}$ & $-0,232(p=0,097)$ \\
\hline
\end{tabular}

* Pearson correlation coefficient with a $p<0.05$ 


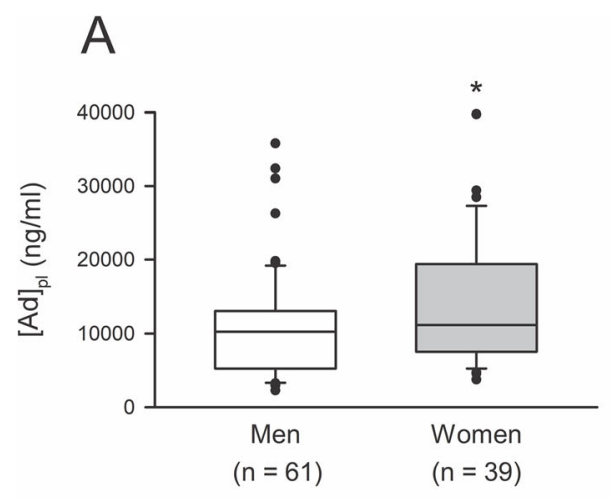

B

C
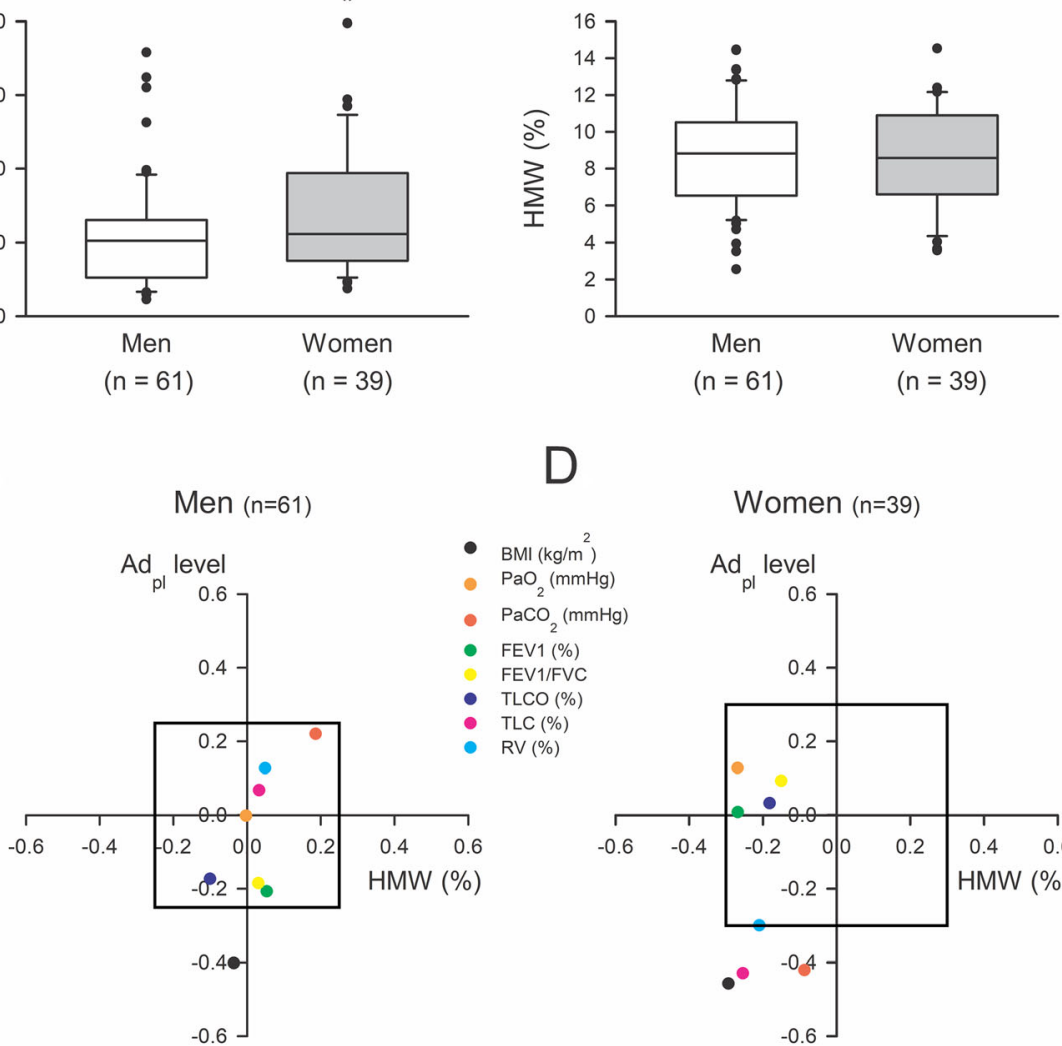

D

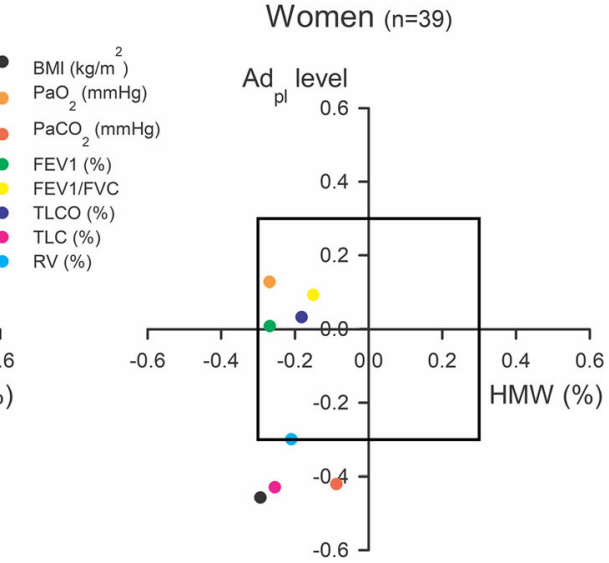

$\mathrm{E}$

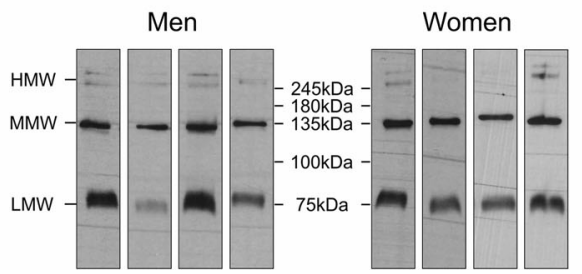

Fig. 2 a-b Adpl level (a) and HMW form proportion (b) in men and women COPD patients. Adpl level was measured by ELISA and HMW form proportion was determined using a non-denaturing PAGE-SDS followed by a Western blot. Data were represented as boxplots (5th and 95th percentiles). ${ }^{*} p<0.05$; Rank-Sum test. c-d Correlation between $\mathrm{Ad}_{\mathrm{pl}}$ level (vertical), or HMW form proportion (horizontal) and lung function parameters in men (a) and women (b) COPD patients. Pearson correlation coefficients (R) between every parameter and either Adpl level or HMW form proportion were calculated and reported as a point on the graph. The box in the graph represents the critical value for Pearson correlation coefficient to obtain a $p<0.05$. Therefore, every point outside the box corresponds to a significant correlation. e Representative blots of Ad form proportion in men and women, determined by using non-denaturant PAGE-SDS followed by a Western blot. HMW forms correspond to the higher molecular weight bands. Admer/total Ad ratios were obtained after densitometric analysis

and RV \%pv in women, reflecting hyperinflation and airtrapping respectively.

The increased TLC \%pv was correlated with a reduced $\mathrm{Ad}_{\mathrm{pl}}$ level. As pro-inflammatory cytokines were previously demonstrated to reduce Ad expression in adipocytes [44], it could be hypothesised that inflammatory state in these patients modulates $\mathrm{Ad}_{\mathrm{pl}}$ level. Indeed, Rubinsztajn et al. observed that patients with hyperinflation had elevated inflammatory markers [21]. Another explanation supporting this hypothesis could be the gender difference in inflammatory processes [45-47]. The exact mechanism remains unclear. Rathod et al. showed that a divergent hormonal status could be involved in this regulation [46], whereas the study of Casimir et al. observed that some genes on $\mathrm{X}$ chromosome, involved in the inflammatory pathway, were overexpressed in women [45]. While this divergence in the inflammatory state was not previously described in COPD, this 
Table 3 Correlation between lung function parameters and $\mathrm{Ad}_{\mathrm{pl}}$ level or HMW form proportion in men and women COPD patients. $\mathrm{Ad}_{\mathrm{pl}}$ level was measured by ELISA and HMW form proportion was determined using a non-denaturing PAGE-SDS followed by a Western blot. Data were represented as Pearson correlation coefficient ( $p$ value)

\begin{tabular}{|c|c|c|c|c|}
\hline \multirow[b]{2}{*}{ Correlation } & \multicolumn{2}{|l|}{ Ad $_{\mathrm{pl}}$ level } & \multicolumn{2}{|c|}{ HMW form proportion (\%) } \\
\hline & Men $(n=61)$ & Women $(n=39)$ & Men $(n=61)$ & Women $(n=39)$ \\
\hline BMI $\left(\mathrm{kg} / \mathrm{m}^{2}\right)$ & $-0,402^{*}(p=0,001)$ & $-0,458^{*}(p=0,003)$ & $-0,036_{(p=0,783)}$ & $-0,293(p=0,070)$ \\
\hline $\mathrm{PaO}_{2}(\mathrm{mmHg})$ & $-0,002(p=0,989)$ & $0,127(p=0,440)$ & $-0,003(0,984)$ & $-0,269(p=0,098)$ \\
\hline $\mathrm{PaCO}_{2}(\mathrm{mmHg})$ & $0,220_{(p=0,0913)}$ & $-0,421^{*}(p=0,008)$ & $0,186_{(p=0,155)}$ & $-0,087(p=0,603)$ \\
\hline FEV1 (\%pv) & $-0,208(p=0,109)$ & $0,008(p=0,962)$ & $0,054(p=0,682)$ & $-0,268(p=0,099)$ \\
\hline FEV1/FVC & $-0,185(p=0,153)$ & $0,093(p=0,575)$ & $0,031_{(p=0,814)}$ & $-0,150(p=0,362)$ \\
\hline $\mathrm{TL}_{\mathrm{CO}}(\% \mathrm{pv})$ & $-0,174(p=0,181)$ & $0,032(p=0,851)$ & $-0,100(p=0,441)$ & $-0,182(p=0,282)$ \\
\hline TLC (\%pv) & $0,067(p=0,622)$ & $-0,429^{*}(p=0,007)$ & $0,033(p=0,811)$ & $-0,254(p=0,124)$ \\
\hline RV (\%pv) & $0,127(p=0,352)$ & $-0,300(p=0,067)$ & $0,049(p=0,721)$ & $-0,210(p=0,206)$ \\
\hline
\end{tabular}

* Pearson correlation coefficient with a $p<0.05$

phenomenon is well known in patients with asthma, with a more pronounced inflammatory response within the airway wall in women [48-50]. Therefore, more studies are necessary for elucidating the potential role of inflammation in the association between $\mathrm{Ad}_{\mathrm{pl}}$ level and TLC \%pv in women with COPD.

Moreover, $\mathrm{Ad}_{\mathrm{pl}}$ level in women was negatively associated with $\mathrm{PaCO}_{2}$, especially in the hypoxemic subgroup. These observations are consistent with previous studies that found a decreased $\mathrm{Ad}_{\mathrm{pl}}$ level and a higher $\mathrm{PaCO}_{2}$ in mice with acute lung injury [51] or in patients with hypoventilation syndrome [52]. Moreover, Dimoulis et al. observed that $\mathrm{Ad}_{\mathrm{pl}}$ level was negatively correlated with bicarbonate level [53]. They also found that, in stable hypercapnic COPD, non-invasive ventilation reduced $\mathrm{PaCO}_{2}$ and increased $\mathrm{PaO}_{2}$ and $\mathrm{Ad}_{\mathrm{pl}}$ level from the first month of intervention, without any change in BMI [54]. Therefore, our study suggested that functional alterations such as hyperinflation, air trapping and impaired gas exchange also modulated $\mathrm{Ad}_{\mathrm{pl}}$ level in COPD patients.

In addition to its potential modulation of $\mathrm{Ad}_{\mathrm{pl}}$ level through its association with hypercapnia, hypoxaemia was associated to an increased level of HMW forms in women. Interestingly, these observations were in accordance with our previous study in which an increased HMW form proportion in a murine model of hypoxaemia was observed [34]. In this model, the only difference between the active and control groups was the exposure to hypoxia. However, we also observed that the increased HMW form proportion was associated to a decreased AdipoR protein level in different tissues $[55,56]$. Further studies are therefore needed to better understand the impact of an increased level of HMW forms in hypoxemic women. No modulation of $\mathrm{Ad}_{\mathrm{pl}}$ level or HMW form proportion were observed among hypoxemic and non-hypoxemic men, suggesting that Ad is modulated by different mechanisms in men and women. One explanation could be the presence of a gender-difference in the inflammatory response, as previously mentioned. Indeed, in different pathological contexts, previous studies reported that women were affected to a more extended level by a proinflammatory state but respond more vigorously [57-59].

Altogether, our results suggested that gender difference in $\mathrm{Ad}_{\mathrm{pl}}$ level observed in our COPD patients could
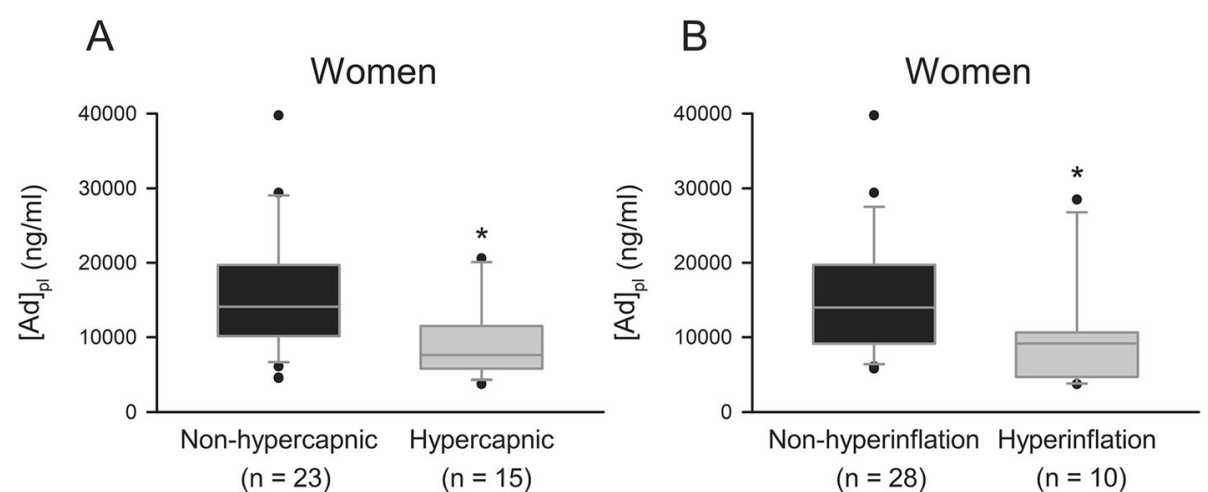

Fig. $3 \mathrm{Ad}_{\mathrm{pl}}$ level in women with or without hypercapnia (a) or lung hyperinflation (b). Ad level was measured by ELISA. Data were represented as boxplots (5th and 95th percentiles). ${ }^{*} p<0.05$; Rank-Sum test 

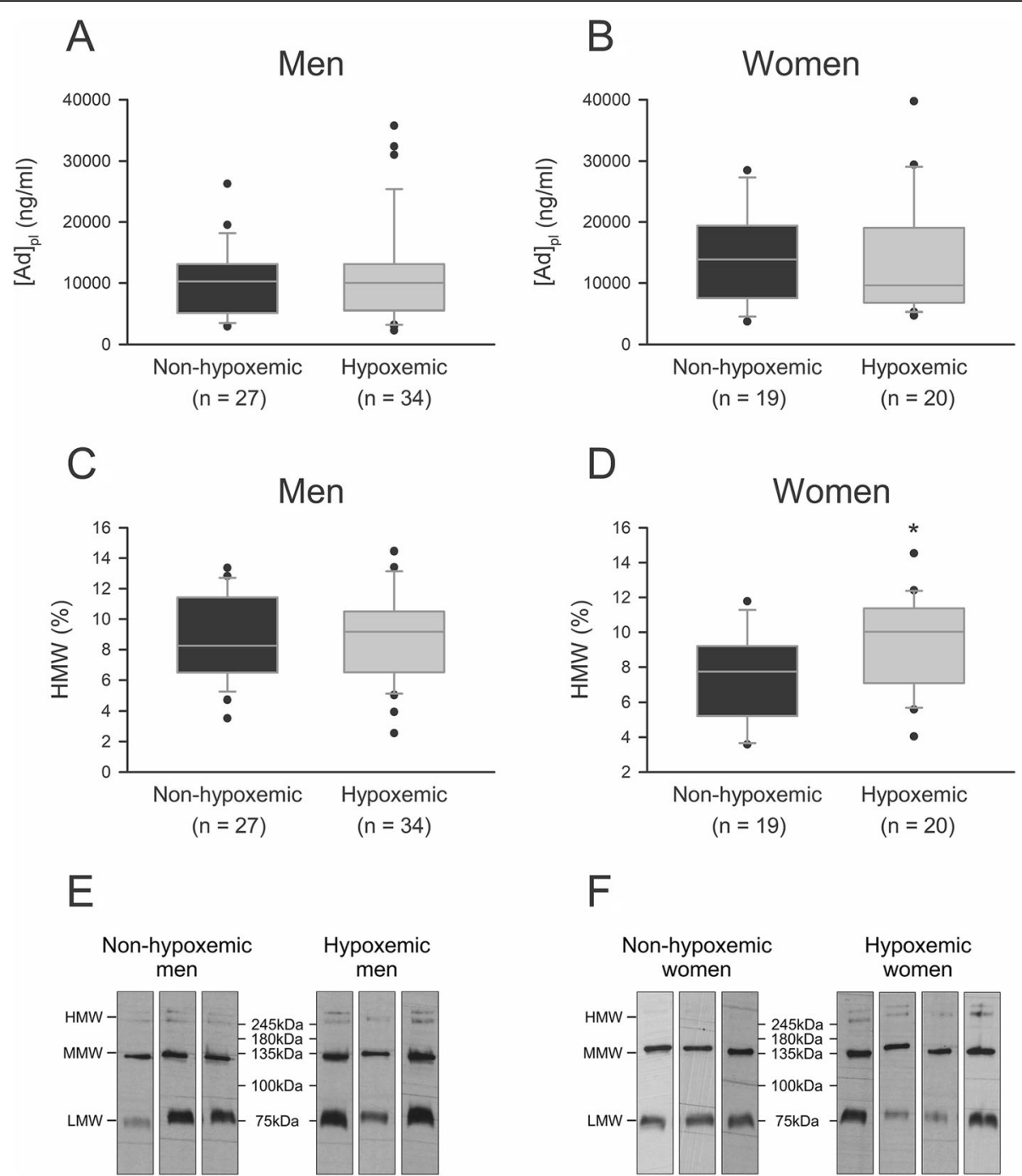

Fig. $4 \mathrm{Ad}_{\mathrm{pl}}$ level (a-b) and HMW form proportion (c-d) in hypoxemic and non-hypoxemic men and women COPD patients. Adpl level was measured by ELISA and HMW form proportion was determined using a non-denaturing PAGE-SDS followed by a Western blot. Data were represented as boxplots (5th and 95th percentiles). ${ }^{*} p<0.05$; Rank-Sum test. e-f Representative blots of Ad form proportion in non-hypoxemic and hypoxemic men (e) as well as in non-hypoxemic and hypoxemic women (f). HMW form proportion was determined by using non-denaturant PAGE-SDS followed by a Western blot and corresponds to the higher molecular weight bands. Admer/total Ad ratios were obtained after densitometric analysis

be explained by a divergent pathophysiology in men and women. Indeed, we observed a gender divergence in TLC and RV, without any difference in BMI. The increase of TLC and RV \%pv observed in women in our study was also found in other recent studies [60-62]. These data suggested that, for a given FEV1, women had a more pronounced air trapping or hyperinflation than men, while hyperinflation was quite limited in our study (mean TLC was $105 \%$ pv in women and $87 \%$ pv in men). These observations are consistent with Grabicki et al. that showed that COPD women had more hyperinflation, air trapping and comorbidities, inducing a higher risk of mortality [61]. In addition, in women, this increased air trapping also led to the development of hypercapnia
[63]. Our results also contrasted with previous studies in which men exhibited more emphysema than women. By using CT scan, previous studies observed that the percentage of low attenuation area was higher in men than in women [64-66]. However, the study of Hardin et al. [67] highlighted that gender difference in CT-determined emphysema is dependent on the severity of airway obstruction (GOLD classification). Despite of these considerations, it is interesting to note that the difference in radiological emphysema did not appear in functional hyperinflation in Martinez's study. These results underlined the contrast between radiological evaluations in favour of more emphysema in men, and functional measures reflecting probably a higher air trapping in women. This study has some 

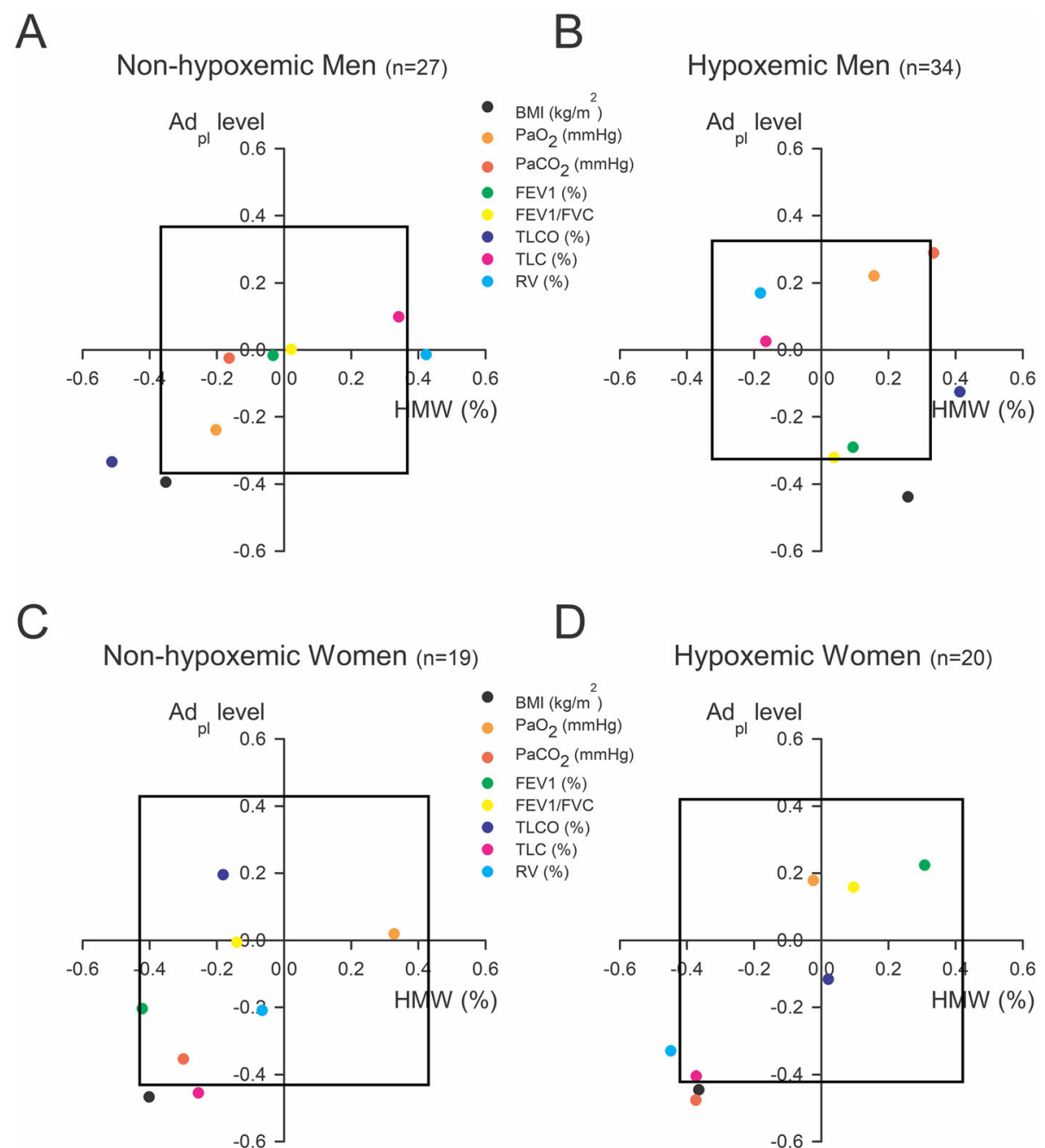

$\mathrm{D}$

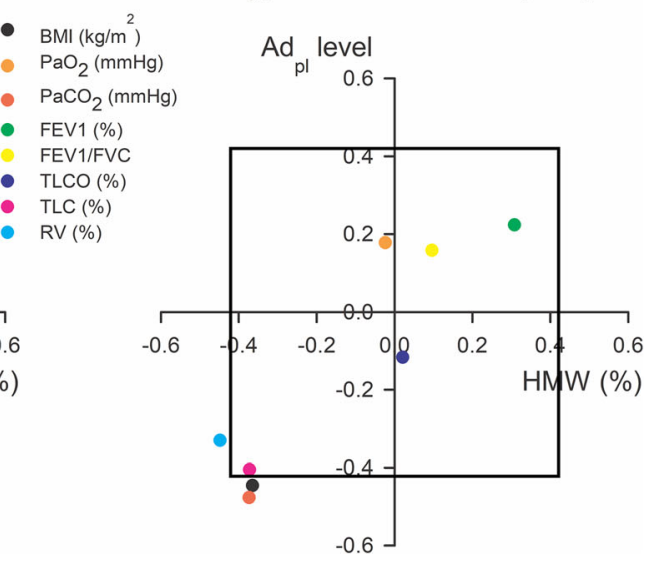

Fig. 5 Relationship between Adpl level, (vertical), HMW form proportion (horizontal) and lung function parameters in non-hypoxemic men (a), hypoxemic men (b), non-hypoxemic women (c) and hypoxemic women (d) COPD patients. Adpl level was measured by ELISA and HMW form proportion was determined using a non-denaturing PAGE-SDS followed by a Western blot. Pearson correlation coefficients (R) between every parameter and either $\mathrm{Ad}_{\mathrm{pl}}$ level or HMW form proportion were calculated and were represented as a point on the graph. The box in the graph represents the critical value for Pearson correlation coefficient to obtain a $p<0.05$. Therefore, every point outside the box corresponds to a significant correlation

Table 4 Correlation between lung function parameters and $\mathrm{Ad}_{\mathrm{pl}}$ level in hypoxemic and non-hypoxemic men and women COPD patients. $\mathrm{Ad}_{\mathrm{pl}}$ level was measured by ELISA and HMW form proportion was determined using a non-denaturing PAGE-SDS followed by a Western blot. Data were represented as Pearson correlation coefficient ( $p$ value)

\begin{tabular}{|c|c|c|c|c|}
\hline \multirow[b]{2}{*}{ Correlation } & \multicolumn{2}{|l|}{ Ad $_{\mathrm{pl}}$ level } & \multicolumn{2}{|l|}{ Ad $_{\mathrm{pl}}$ level } \\
\hline & Non-hypoxemic Men $(n=27)$ & Hypoxemic Men $(n=34)$ & Non-hypoxemic Women $(n=19)$ & Hypoxemic Women $(n=20)$ \\
\hline BMI $\left(\mathrm{kg} / \mathrm{m}^{2}\right)$ & $-0,395^{*}(p=0,042)$ & $-0,439^{*}(p=0,009)$ & $-0,467^{*}(p=0,044)$ & $-0,446^{*}(P=0,049)$ \\
\hline $\mathrm{PaO}_{2}(\mathrm{mmHg})$ & $-0,239(p=0,231)$ & $0,221(p=0,210)$ & $0,019(p=0,939)$ & $0,177(p=0,454)$ \\
\hline $\mathrm{PaCO}_{2}(\mathrm{mmHg})$ & $-0,025(p=0,901)$ & $0,288(p=0,104)$ & $-0,355(p=0,136)$ & $-0,477^{*}(p=0,039)$ \\
\hline FEV1 (\%pv) & $-0,017(p=0,932)$ & $-0,290(p=0,096)$ & $-0,204(p=0,401)$ & $0,223(p=0,344)$ \\
\hline FEV1/FVC & $0,001(p=0,995)$ & $-0,321(p=0,064)$ & $-0,006_{(p=0,981)}$ & $0,158(p=0,506)$ \\
\hline $\mathrm{TL}_{\mathrm{CO}}(\% \mathrm{pv})$ & $-0,334(0,095)$ & $-0,126_{(p=0,478)}$ & $0,195(p=0,454)$ & $-0,116_{(p=0,625)}$ \\
\hline TLC (\%pv) & $0,098(p=0,647)$ & $0,025(p=0,892)$ & $-0,455^{*}(p=0,05)$ & $-0,405(p=0,076)$ \\
\hline RV (\%pv) & $-0,014_{(p=0,947)}$ & $0,169(p=0,354)$ & $-0,209(p=0,404)$ & $-0,331(p=0,155)$ \\
\hline
\end{tabular}

* Pearson correlation coefficient with a $p<0.05$ 
Table 5 Correlation between lung function parameters and HMW form proportion in hypoxemic and non-hypoxemic men and women COPD patients. Ad level was measured by ELISA and HMW form proportion was determined using a non-denaturing PAGE-SDS followed by a Western blot. Data were represented as Pearson correlation coefficient ( $p$ value)

\begin{tabular}{|c|c|c|c|c|}
\hline \multirow[b]{2}{*}{ Correlation } & \multicolumn{2}{|l|}{ HMW form proportion (\%) } & \multicolumn{2}{|l|}{ HMW form proportion (\%) } \\
\hline & Non-hypoxemic Men $(n=27)$ & Hypoxemic Men $(n=34)$ & Non-hypoxemic Women $(n=19)$ & Hypoxemic Women $(n=20)$ \\
\hline BMI $\left(\mathrm{kg} / \mathrm{m}^{2}\right)$ & $-0,352_{(p=0,072)}$ & $0,258(p=0,141)$ & $-0,401_{(p=0,088)}$ & $-0,365(p=0,114)$ \\
\hline $\mathrm{PaO}_{2}(\mathrm{mmHg})$ & $-0,202(p=0,311)$ & $0,157(p=0,374)$ & $0,328(p=0,170)$ & $-0,023(p=0,922)$ \\
\hline $\mathrm{PaCO}_{2}(\mathrm{mmHg})$ & $-0,163(p=0,416)$ & $0,335(p=0,057)$ & $-0,299(p=0,213)$ & $-0,373(p=0,116)$ \\
\hline FEV1 (\%pv) & $-0,032(p=0,874)$ & $0,095(p=0,593)$ & $-0,422(p=0,072)$ & $0,308(p=0,186)$ \\
\hline FEV1/FVC & $0,022_{(p=0,915)}$ & $0,039(p=0,829)$ & $-0,140(p=0,568)$ & $0,096(p=0,686)$ \\
\hline $\mathrm{TL}_{\mathrm{CO}}(\% \mathrm{pv})$ & $-0,513^{*}(p=0,007)$ & $0,413^{*}(p=0,015)$ & $-0,181(p=0,487)$ & $0,021(p=0,930)$ \\
\hline TLC (\%pv) & $0,341(p=0,102)$ & $-0,165(p=0,367)$ & $-0,255(p=0,308)$ & $-0,372(p=0,106)$ \\
\hline RV (\%pv) & $0,423^{*}(p=0,039)$ & $-0,181(p=0,321)$ & $-0,065(p=0,798)$ & $-0,448^{*}(p=0,047)$ \\
\hline
\end{tabular}

* Pearson correlation coefficient with a $p<0.05$

limitations. As we evaluated the effect of the hypoxaemia component in COPD patient, we separated our cohort according to the $\mathrm{PaO}_{2}$ ( $\leq 55 \mathrm{mmHg}$ ). However, patients in such severe condition received LTOT in order to reduce the risk of complications and mortality. It was therefore difficult to tolerate a washing period from oxygen therapy for those already on this treatment at the inclusion time. Treatment-naive patients should be selected and modulation of $\mathrm{Ad}_{\mathrm{pl}}$ level and HMW form proportion could then be studied before and after LTOT in the same patient. In our study, the main confounding factors (age, BMI, gender) affecting $\mathrm{Ad}_{\mathrm{pl}}$ level in COPD patients [68], were taken into consideration. However, we cannot exclude any influence of other concomitant factors such as medication, physical activity or cardio-vascular co-morbidities.

\section{Conclusions}

Altogether, these data suggested that men and women with severe hypoxaemia exhibited a different pathophysiology of COPD, which is linked to Ad modulation. Indeed, an increased $\mathrm{Ad}_{\mathrm{pl}}$ level was observed in COPD women and was associated with a distinct pattern of functional alterations (for the same age, BMI or obstruction severity): women had more hyperinflation, air-trapping and hypercapnia, which, in association with hypoxaemia, could contribute to a modulation of $\mathrm{Ad}_{\mathrm{pl}}$ level. These variations were accompanied with an increased level of HMW forms in hypoxemic women. All these results suggest the development of a distinct endotypic presentation, based on gender, with a more pronounced bronchiolar damages possibly associated with an inflammatory state, leading to an increased airtrapping. Consequently, a long-term study should be realized to evaluate if these modulations of total $\mathrm{Ad}_{\mathrm{pl}}$ and HMW forms are associated with a better survival or with a lower risk of comorbidities.

\section{Supplementary information}

Supplementary information accompanies this paper at https://doi.org/10. 1186/s12890-020-01288-3.

\section{Additional file 1.}

Additional file 2.

\begin{abstract}
Abbreviations
Ad: Adiponectin; Adpl: Ad plasmatic; COPD: Chronic obstructive pulmonary disease; CVD: Cardiovascular diseases; FEV1: Forced expiratory volume in one second; FVC: Forced vital capacity; HMW: High molecular weight; IC: Inspiratory capacity; LMW: Low molecular weight; MMW: Medium molecular weight; $\mathrm{PaO}_{2}$ : Arterial oxygen partial pressure; $\mathrm{PaCO}_{2}$ : Carbon dioxide partial pressure; R: Pearson correlation coefficient; RV: Residual volume; TLC: Total lung capacity; TLco: Carbon monoxide transfer factor; $\% p v$ : Percentage of the predicted value
\end{abstract}

\section{Acknowledgements}

We acknowledge V. Jenart and B. Blairon, for technical assistance.

\section{Authors' contributions}

MP carried out the molecular studies, participated in the design of the study, drafted the manuscript and performed data recording, data analyses, and the statistical analyses. AT participated in the conception of the study and in its design and coordination. AT also supervised molecular studies, critically revised the manuscript and found sustaining funds for project. AL1 participated in study coordination, data recording and analysis. AL2 conceived of the study, and participated in its design and coordination, helped to draft the manuscript and to perform statistical analysis. All authors have read and approved the final manuscript.

\section{Funding}

FRMH (Fonds pour la Recherche Médicale dans le Hainaut) provided funding that helps us to perform Western blot and ELISA analyses. MP held PhD fellowships from the University of Mons.

\section{Availability of data and materials}

The datasets supporting the conclusion of this article are included within the article and its additional file.

\section{Ethics approval and consent to participate}

This study was approved by the Erasme Hospital Ethics Committee. All procedures were conducted in accordance with ACCP/ATS/ERS guidelines. All patients had previously given their written informed consent for this study.

Consent for publication Not Applicable. 


\section{Competing interests}

The authors declare that they have no conflict of interest regarding the publication of this paper. Each author meets the criteria for authorship and assumes the corresponding responsibility.

\section{Received: 10 February 2020 Accepted: 15 September 2020 Published online: 01 October 2020}

\section{References}

1. Kent BD, Mitchell PD, McNicholas WT. Hypoxemia in patients with COPD: cause, effects, and disease progression. Int J Chron Obstruct Pulmon Dis. 2011;6:199-208.

2. Maclay JD, McAllister DA, Macnee W. Cardiovascular risk in chronic obstructive pulmonary disease. Respirology. 2007;12(5):634-41.

3. Kamil F, Pinzon I, Foreman MG. Sex and race factors in early-onset COPD. Curr Opin Pulm Med. 2013;19(2):140-4.

4. Han MK, Postma D, Mannino DM, Giardino ND, Buist S, Curtis JL, et al. Gender and chronic obstructive pulmonary disease. Am J Respir Crit Care Med. 2007;176(12):1179-84

5. Raherison C, Biron E, Nocent-Ejnaini C, Taillé C, Tillie-Leblond I, Prudhomme A. Are there specific characteristics of COPD in women? Rev Mal Respir. 2010;27(6):611-24

6. Kanner RE, Connett JE, Altose MD, Buist AS, Lee WW, Tashkin DP, et al. Gender difference in airway hyperresponsiveness in smokers with mild COPD. The lung health study. Am J Respir Crit Care Med. 1994;150(4): 956-61.

7. Amaral AFS, Strachan DP, Burney PGJ, Jarvis DL. Female smokers are at greater risk of airflow obstruction than male smokers. UK biobank. Am J Respir Crit Care Med. 2017;195(9):1226-35.

8. Hogg JC, Chu F, Utokaparch S, Woods R, Elliott WM, Buzatu L, et al. The nature of small-airway obstruction in chronic obstructive pulmonary disease. N Engl J Med. 2004;350(26):2645-53.

9. Sayiner A, Hague C, Ajlan A, Leipsic J, Wierenga L, Krowchuk NM, et al. Bronchiolitis in young female smokers. Respir Med. 2013;107(5):732-8.

10. Sawalha S, Hedman L, Backman H, Stenfors N, Rönmark E, Lundbäck B, et al. The impact of comorbidities on mortality among men and women with COPD: report from the OLIN COPD study. Ther Adv Respir Dis. 2019;13: 1753466619860058.

11. Kadowaki T, Yamauchi T, Kubota N, Hara K, Ueki K, Tobe K. Adiponectin and adiponectin receptors in insulin resistance, diabetes, and the metabolic syndrome. J Clin Invest. 2006;116(7):1784-92.

12. Swarbrick MM, Havel PJ. Physiological, pharmacological, and nutritional regulation of circulating Adiponectin concentrations in humans. Metab Syndr Relat Disord. 2008;6(2):87-102.

13. Lara-Castro C, Luo N, Wallace P, Klein RL, Garvey WT. Adiponectin multimeric complexes and the metabolic syndrome trait cluster. Diabetes. 2006:55(1):249-59.

14. Yamauchi T, Kadowaki T. Adiponectin receptor as a key player in healthy longevity and obesity-related diseases. Cell Metab. 2013;17(2):185-96.

15. Ebrahimi-Mamaeghani M, Mohammadi S, Arefhosseini SR, Fallah P, Bazi Z. Adiponectin as a potential biomarker of vascular disease. Vasc Health Risk Manag. 2015;11:55-70.

16. Xie J, Yang $X-Y$, Shi J-D, Deng $X-Q$, Long W. A new inflammation marker of chronic obstructive pulmonary disease-adiponectin. World J Emerg Med. 2010;1(3):190-5.

17. Uzum AK, Aydin MM, Tutuncu Y, Omer B, Kiyan E, Alagol F. Serum ghrelin and adiponectin levels are increased but serum leptin level is unchanged in low weight chronic obstructive pulmonary disease patients. Eur J Intern Med. 2014:25(4):364-9.

18. Breyer M-K, Rutten EPA, Locantore NW, Watkins ML, Miller BE, Wouters EFM, et al. Dysregulated adipokine metabolism in chronic obstructive pulmonary disease. Eur J Clin Invest. 2012;42(9):983-91.

19. Bianco A, Nigro E, Monaco ML, Matera MG, Scudiero O, Mazzarella G, et al. The burden of obesity in asthma and COPD: role of adiponectin. Pulm Pharmacol Ther. 2017:43:20-5.

20. Jaswal S, Saini V, Kaur J, Gupta S, Kaur H, Garg K. Association of adiponectin with lung function impairment and disease severity in chronic obstructive pulmonary disease. Int J Appl Basic Med Res. 2018:8(1):14

21. Rubinsztajn R, Przybyłowski T, Maskey-Warzęchowska M, Paplińska-Goryca M, Karwat K, Nejman-Gryz P, et al. Correlation between hyperinflation defined as an elevated RV/TLC ratio and body composition and cytokine profile in patients with chronic obstructive pulmonary disease. Pneumonol Alergol Pol. 2015;83(2):120-5.

22. Wert SE. Does adiponectin play a role in pulmonary emphysema? Am J Physiol Lung Cell Mol Physiol. 2008;294(6):L1032-4.

23. Guo Q, Jin S, Hu H, Zhou Y, Yan Y, Zong H, et al. Hypoxia in 3T3-L1 adipocytes suppresses adiponectin expression via the PERK and IRE1 unfolded protein response. Biochem Biophys Res Commun. 2017;493(1): 346-51.

24. Ye J, Gao Z, Yin J, He Q. Hypoxia is a potential risk factor for chronic inflammation and adiponectin reduction in adipose tissue of Ob/Ob and dietary obese mice. Am J Physiol Endocrinol Metab. 2007;293(4):E1118-28.

25. Pan G, Su M, Ding W, Ding N, Huang H, Zhang X. Effects of chronic intermittent hypoxia on oxidative stress and inflammatory response and the interventional roles of adiponectin. Zhonghua Yi Xue Za Zhi. 2015;95(16): $1218-21$.

26. Sato K, Shibata Y, Abe S, Inoue S, Igarashi A, Yamauchi K, et al. Association between plasma adiponectin levels and decline in forced expiratory volume in $1 \mathrm{~s}$ in a general Japanese population: the Takahata study. Int J Med Sci. 2014;11(8):758-64.

27. Barrecheguren M, Miravitlles M. COPD heterogeneity: implications for management. Multidiscip Respir Med. 2016;11 [cited 2020 Jun 18]. Available from: https://www.ncbi.nlm.nih.gov/pmc/articles/PMC4794904/.

28. Qaseem A, Wilt TJ, Weinberger SE, Hanania NA, Criner G, van der Molen T, et al. Diagnosis and management of stable chronic obstructive pulmonary disease: a clinical practice guideline update from the American College of Physicians, American College of Chest Physicians, American Thoracic Society, and European Respiratory Society. Ann Intern Med. 2011;155(3): 179-91.

29. Global Initiative for Chronic Obstructive Lung Disease. Gold Reports 2020. 2020 [cited 2020 Jun 19]. Available from: https://goldcopd.org/gold-reports/.

30. Macintyre N, Crapo RO, Viegi G, Johnson DC, van der Grinten CPM, Brusasco $\mathrm{V}$, et al. Standardisation of the single-breath determination of carbon monoxide uptake in the lung. Eur Respir J. 2005;26(4):720-35.

31. Wanger J, Clausen JL, Coates A, Pedersen OF, Brusasco V, Burgos F, et al. Standardisation of the measurement of lung volumes. Eur Respir J. 2005; 26(3):511-22.

32. Miller MR, Hankinson J, Brusasco V, Burgos F, Casaburi R, Coates A, et al. Standardisation of spirometry. Eur Respir J. 2005:26(2):319-38.

33. Pierard $\mathrm{M}$, Conotte $\mathrm{S}$, Tassin A, Boutry S, Uzureau P, Boudjeltia KZ, et al. Interactions of exercise training and high-fat diet on adiponectin forms and muscle receptors in mice. Nutr Metab (Lond). 2016;13 [cited 2017 Jun 22]. Available from: http://www.ncbi.nlm.nih.gov/pmc/articles/PMC5094086/.

34. Pierard M, Tassin A, Conotte S, Zouaoui Boudjeltia K, Legrand A. Sustained intermittent hypoxemia induces Adiponectin oligomers redistribution and a tissue-specific modulation of Adiponectin receptor in mice. Front Physiol. 2019;10 [cited 2019 Feb 13]. Available from: https://www.frontiersin.org/ articles/10.3389/fphys.2019.00068/full.

35. Song HJ, Oh S, Quan S, Ryu O-H, Jeong J-Y, Hong K-S, et al. Gender differences in adiponectin levels and body composition in older adults: Hallym aging study. BMC Geriatr. 2014;14:8.

36. Eglit T, Lember M, Ringmets I, Rajasalu T. Gender differences in serum highmolecular-weight adiponectin levels in metabolic syndrome. Eur J Endocrinol. 2013;168(3):385-91.

37. Sun Y, Xun K, Wang C, Zhao H, Bi H, Chen X, et al. Adiponectin, an unlocking adipocytokine. Cardiovasc Ther. 2009;27(1):59-75.

38. Breyer M-K, Rutten EPA, Vernooy JHJ, Spruit MA, Dentener MA, van der Kallen C, et al. Gender differences in the adipose secretome system in chronic obstructive pulmonary disease (COPD): a pivotal role of leptin. Respir Med. 2011;105(7):1046-53.

39. Frederiksen L, Højlund K, Hougaard DM, Mosbech TH, Larsen R, Flyvbjerg A, et al. Testosterone therapy decreases subcutaneous fat and adiponectin in aging men. Eur J Endocrinol. 2012;166(3):469-76.

40. Horenburg S, Fischer-Posovszky P, Debatin K-M, Wabitsch M. Influence of sex hormones on adiponectin expression in human adipocytes. Horm Metab Res. 2008;40(11):779-86.

41. Nishizawa $H$, Shimomura I, Kishida K, Maeda N, Kuriyama H, Nagaretani H, et al. Androgens decrease plasma adiponectin, an insulin-sensitizing adipocyte-derived protein. Diabetes. 2002;51(9):2734-41.

42. Page ST, Herbst KL, Amory JK, Coviello AD, Anawalt BD, Matsumoto AM, et al. Testosterone administration suppresses adiponectin levels in men. J Androl. 2005;26(1):85-92 
43. Geer EB, Shen W. Gender differences in insulin resistance, body composition, and energy balance. Gend Med. 2009;6(Suppl 1):60-75

44. Ouchi N, Walsh K. Adiponectin as an anti-inflammatory factor. Clin Chim Acta. 2007:380(1-2):24-30.

45. Casimir GJ, Heldenbergh F, Hanssens L, Mulier S, Heinrichs C, Lefevre N, et al. Gender differences and inflammation: an in vitro model of blood cells stimulation in prepubescent children. J Inflamm (Lond). 2010;7:28.

46. Rathod K, Kapil V, Velmurugan S, Khambata R, Siddique U, Khan S, et al. Sex differences in the inflammatory response and inflammation-induced vascular dysfunction. Lancet. 2017;389:S20.

47. Diodato MD, Knöferl MW, Schwacha MG, Bland Kl, Chaudry IH. Gender differences in the inflammatory response and survival following haemorrhage and subsequent sepsis. Cytokine. 2001;14(3):162-9.

48. Zein JG, Erzurum SC. Asthma is different in women. Curr Allergy Asthma Rep. 2015;15(6):28

49. Fuseini $H$, Newcomb DC. Mechanisms driving gender differences in asthma. Curr Allergy Asthma Rep. 2017;17(3):19.

50. Postma DS. Gender differences in asthma development and progression. Gend Med. 2007;4 Suppl B:S133-46.

51. Xu L, Bao H-G, Si Y-N, Han L, Zhang R, Cai M-M, et al. Effects of adiponectin on acute lung injury in cecal ligation and puncture-induced sepsis rats. J Surg Res. 2013;183(2):752-9.

52. Borel J, Roux-Lombard P, Tamisier R, Arnaud C, Monneret D, Arnol N, et al. Endothelial dysfunction and specific systemic inflammation in obesity hypoventilation syndrome. In: C20 endothelial dysfunction and beyond in sleep disordered breathing: American Thoracic Society; 2009. p. A3983. [cited 2018 Oct 3]. (American Thoracic Society International Conference Abstracts). Available from: https://www.atsjournals.org/doi/abs/10.1164/ ajrccm-conference.2009.179.1_MeetingAbstracts.A3983.

53. Dimoulis A, Pastaka C, Tsolaki V, Tsilioni I, Pournaras S, Liakos N, et al. Non-invasive ventilation (NIV) and homeostatic model assessment (HOMA) index in stable chronic obstructive pulmonary disease (COPD) patients with chronic Hypercapnic respiratory failure: a pilot study. COPD. 2015;12(4):427-34.

54. Ryo M, Nakamura T, Kihara S, Kumada M, Shibazaki S, Takahashi M, et al. Adiponectin as a biomarker of the metabolic syndrome. Circ J. 2004;68(11):975-81.

55. Van Berendoncks AM, Garnier A, Beckers P, Hoymans VY, Possemiers N, Fortin $\mathrm{D}$, et al. Functional adiponectin resistance at the level of the skeletal muscle in mild to moderate chronic heart failure. Circ Heart Fail. 2010;3(2):185-94.

56. Li R, Xu M, Wang X, Wang Y, Lau WB, Yuan Y, et al. Reduced vascular responsiveness to adiponectin in hyperlipidemic rats--mechanisms and significance. J Mol Cell Cardiol. 2010;49(3):508-15.

57. Spitzer JA, Zhang P. Gender differences in neutrophil function and cytokineinduced neutrophil chemoattractant generation in endotoxic rats. Inflammation. 1996;20(5):485-98.

58. Casimir GJA, Duchateau J. Gender differences in inflammatory processes could explain poorer prognosis for males. J Clin Microbiol. 2011;49(1):478-9.

59. Onat A, Karadeniz Y, Tusun E, Yüksel H, Kaya A. Advances in understanding gender difference in cardiometabolic disease risk. Expert Rev Cardiovasc Ther. 2016;14(4):513-23.

60. Verhage TL, Heijdra Y, Molema J, Vercoulen J, Dekhuijzen R. Associations of muscle depletion with health status. Another gender difference in COPD? Clin Nutr. 2011;30(3):332-8.

61. Grabicki M, Kuźnar-Kamińska B, Rubinsztajn R, Brajer-Luftmann B, Kosacka M, Nowicka A, et al. COPD course and comorbidities: are there gender differences? Adv Exp Med Biol. 2019;1113:43-51.

62. Laviolette L, Lacasse Y, Doucet M, Lacasse M, Marquis K, Saey D, et al. Chronic obstructive pulmonary disease in women. Can Respir J. 2007;14(2):93-8.

63. Shade D, Cordova F, Lando Y, Travaline JM, Furukawa S, Kuzma AM, et al. Relationship between resting hypercapnia and physiologic parameters before and after lung volume reduction surgery in severe chronic obstructive pulmonary disease. Am J Respir Crit Care Med. 1999;159(5 Pt 1): 1405-11.

64. Camp PG, Coxson HO, Levy RD, Pillai SG, Anderson W, Vestbo J, et al. Sex differences in emphysema and airway disease in smokers. Chest. 2009; 136(6):1480-8

65. Dransfield MT, Washko GR, Foreman MG, Estepar RSJ, Reilly J, Bailey WC. Gender differences in the severity of CT emphysema in COPD. Chest. 2007; 132(2):464-70
66. Martinez FJ, Curtis JL, Sciurba F, Mumford J, Giardino ND, Weinmann G, et al. Sex differences in severe pulmonary emphysema. Am J Respir Crit Care Med. 2007;176(3):243-52.

67. Hardin M, Foreman M, Dransfield MT, Hansel N, Han MK, Cho MH, et al. Sexspecific features of emphysema among current and former smokers with COPD. Eur Respir J. 2016;47(1):104-12.

68. Lin Y-H, Jiang T-X, Hu S-X, Shi Y-H. Association between serum adiponectin concentrations and chronic obstructive pulmonary disease: a meta-analysis. Biosci Rep. 2020;40(3) [cited 2020 Apr 29]. Available from: https://www.ncbi. nlm.nih.gov/pmc/articles/PMC7069907/

\section{Publisher's Note}

Springer Nature remains neutral with regard to jurisdictional claims in published maps and institutional affiliations.

\section{Ready to submit your research? Choose BMC and benefit from:}

- fast, convenient online submission

- thorough peer review by experienced researchers in your field

- rapid publication on acceptance

- support for research data, including large and complex data types

- gold Open Access which fosters wider collaboration and increased citations

- maximum visibility for your research: over $100 \mathrm{M}$ website views per year

At BMC, research is always in progress.

Learn more biomedcentral.com/submissions 